\title{
Mansikkalajikkeet kehittyvät
}

\author{
Tarja Hietaranta ${ }^{1)}$ ja Ville Matala ${ }^{2)}$ \\ ${ }^{1)}$ MTT puutarhatuotanto,Toivonlinnantie 518,21500 Piikkiö,tarja.hietaranta@mtt.fi \\ ${ }^{2)}$ MTT ekologinen tuotanto, Karilantie 2A, 50600 Mikkeli, \\ nykyinen osoite: Marjaosaamiskeskus, Jalkalantie 6, 77600 Suonenjoki, ville.matala@pp.inet.fi
}

\section{Johdanto}

Puutarhamansikan viljelylajikkeet ovat viime vuosien kuluessa hiljalleen uusiutuneet. Vanhat valtalajikkeet, 'Zefyr' ja 'Senga Sengana', ovat saaneet väistyä Jonsok ja Polka-lajikkeiden tieltä. Myös 'Honeoye', 'Bounty ' ja 'Korona' ovat vallanneet omat osuutensa viljelypinta-aloista. Muutoksen moottoreina ovat olleet pääasiassa tauti- ja talvehtimisongelmat. Toisaalta lajikevalikoimissa voidaan havaita myös suuntaus kohti entistä kiinteämpiä ja kuljetuskestävämpiä lajikkeita. Kipeimmin viljelyyn kaivataan uutta viljelyvarmaa ja maukasta aikaista lajiketta. Puutarhamansikan lajikevalikoimaa on pyritty laajentamaan sekä kotimaisen mansikanjalostuksen että ulkomaisen lajikeaineiston testauksen kautta.

\section{Mansikan jalostus}

Vuonna 1997 Maatalouden tutkimuskeskuksessa aloitettiin uusi, entistä laajempi, mansikan jalostusohjelma. Jalostuksen päätavoitteina ovat härmänkestävyys ja marjan kiinteyden parantaminen. Ohjelman ensivaiheessa lähtökohdaksi on otettu meillä viljelyvarmojen lajikkeiden risteyttäminen härmänkestävien ja/tai kiinteämarjaisten lajikkeiden kanssa. Päätavoitteiden lisäksi jalostuksessa huomioidaan myös monia muita tärkeitä ominaisuuksia, kuten harmaahomeen ja tyvimädän kestävyys, pensaan kasvutapa, satoisuus, marjan muoto, väri ja tietysti maku.

Uuden jalostusohjelman ensimmäiset lajikkeet eivät vielä ole valmiita, mutta vuonna 2003 laskettiin viljelyyn vanhasta mansikan jalostusohjelmasta peräisin oleva aikainen mansikkalajike 'Kaunotar'.

\section{Mansikan lajiketestaus}

Ulkomaista lajikeaineistoa on testattu kaksivaiheisella koejärjestelyillä lajikeseuranta- ja tilakokeissa aina vuodesta 1993 vuoteen 2002. Lajikkeiden alustava arviointi toteutettiin lajikeseurantakokeissa MTT:n puutarhatuotannossa Piikkiössä ja ekologisessa tuotannossa Mikkelissä: suuresta määrästä ulkomaisia uutuuksia seulottiin ne, joiden jatkotestauksen kannatti panostaa. Uusia lajikeseurantakokeita perustettiin vuosittain. Seurantakokeiden lupaavimmat lajikkeet siirrettiin suuremman mittakaavan testaukseen tilakokeisiin, viimeksi "Marjatilojen tuottavuuden parantaminen uusien lajikkeiden avulla" -hankkeen puitteissa. Tällä hetkellä projektitutkimuksena toteutettu tilakoetoiminta on päättynyt, eikä uutta hanketta ole käynnistymässä. Myös mansikan lajikeseuranta on supistumassa. Jatkossa rajoitettu määrä ulkomaisia lajikkeita voidaan arvioida mansikan jalostusaineiston testausta varten perustettavien kokeiden yhteydessä.

\section{Koejärjestelyt}

Kaikissa mansikan lajike- ja jalostusaineistokokeissa koejäsenten satokauden aikaisuutta verrattiin aikaisuusindeksillä, jonka on kehittänyt italialainen jalostaja Walther Faedi. Indeksi ilmoittaa sadon keskimääräisen kypsymisajankohdan. Indeksi lasketaan kertomalla jokaisen korjuupäivän sato korjuupäivän järjestysluvulla ja jakamalla näin saatujen tulojen summa kokonaissadolla. Aikaisuusindeksi ilmoittaa sadon huippukohdan päivämäärän järjestyslukuna vuoden alusta.

\section{Mansikanjalostus - valittujen jalosteiden vertaileva koe}

Kaunotar-lajiketta on testattu kahdessa vertailevassa kokeessa MTT:ssä. Kokeet perustettiin heinäkuussa 1998 Piikkiöön ja Laukaalle. Samoissa kokeessa testattiin myös kahta muuta myöhäisempää jalostetta. Kaikista koejäsenistä istutettiin neljä 14 kasvin koeruutua muovikatteiseen yksirivi-istutukseen, kolme tainta metrille. Piikkiön kokeessa maalaji oli karkea hieta ja Laukaan kokeessa rahkasaraturve. Kokeen kastelut tehtiin sadetuskalustolla päältäkasteluna. Verranteina kokeissa olivat Bounty-ja Senga Sengana lajikkeet. Härmänkestävyyden arvioinnin helpottamiseksi kokeille ei tehty lainkaan härmäntorjuntaa. Harmaahomeentorjunta tehtiin kevennettynä, niin että torjuntaohjelman kolmesta käsittelykerrasta jätettiin kukinnan alussa tehtävä käsittely pois. Koejäsenten kasvusto- ja marjaominaisuuksia havainnointiin ja arvosteltiin Piikkiössä vuosina 1999-2001 ja Laukaassa vuosina 1999-2000. Sato korjattiin ja punnittiin ainoastaan Piikkiössä. 


\section{Lajikeseurantakokeet}

Lajikeuutuuksista perustettiin vuosittain uusia lajikeseurantakokeita. Kokeet perustettiin Piikkiöön, ja rajoitetummalla lajikevalikoimalla, myös Mikkeliin. Kutakin lajiketta istutettiin kokeeseen 30 kasvin erä, ja verrannelajikkeiksi istutettiin 'Bounty' ja 'Jonsok'. Piikkiön kokeissa taimet jaettiin kolmeen kymmenen kasvin koeruutuun ja Mikkelin kokeissa puolestaan kahden viidentoista kasvin koeruutuun. Piikkiön kokeet perustettiin vuodesta 1999 alkaen paririvi-istutuksena mustalla muovilla katettuun matalaan penkkiin. Paririvipenkkien keskelle asennettiin tihkuletku. Taimiväli kokeissa oli 40 senttimetriä ja riviväli 1,4 metriä. Mikkelin kokeissa taimiväli oli yksittäisessä paririvissä 45 senttimetriä. Riviväli oli 1,8 metriä. Koetta kasteltiin sadetuskalustolla päältäkasteluna. Härmänkestävyyden arvioinnin helpottamiseksi näillekään kokeille ei tehty lainkaan härmäntorjuntaa. Harmaahomeentorjunta tehtiin kevennettynä, niin että torjuntaohjelman kolmesta käsittelykerrasta jätettiin kukinnan alussa tehtävä käsittely pois.

\section{Tilakokeet}

Tilakokeet toteutettiin yhteistyössä viljelijöiden kanssa. Ne perustettiin käytännön viljelmille niin, että kullakin koetilalla oli kahdesta neljään uutta koelajiketta, jotka olivat vierekkäisissä riveissä. Lisäksi jokaisella koetilalla oli yksi seuraavista verrannelajikkeista: 'Bounty', 'Honeoye', 'Jonsok', 'Polka' tai 'Senga Sengana'. Kutakin koelajiketta istutettiin 100-200 tainta. Kokeiden hoidossa noudatettiin kukin tilan omaa viljelykäytäntöä.

\section{Uusia lajikkeita mansikanviljelyyn}

\section{'Kaunotar'}

Uusi suomalainen mansikkalajike, 'Kaunotar', on peräisin vuonna 1991 tehdystä Hella- ja Glimalajikkeiden välisestä risteytyksestä. Uutuus on aikainen kuten 'Jonsok' ja Jonsok-lajikkeen tapaan silläkin on taipumusta pienimarjaisuuteen. Tämän vuoksi lajikkeelle suositellaan tihkukastelua, joka edesauttaa marjakoon säilymistä suurempana. Marjan laadun ja maun suhteen 'Kaunotar' on selkeästi Jonsoklajiketta parempi.

Kauppakelpoista satoa Kaunotar-lajike tuotti kokeessa heti istutusta seuraavana vuonna saman verran kuin Bounty-lajike, reilut 200 grammaa. Luku vastaa noin viiden tonnin hehtaarisatoa perinteisessä yksirivi-istutuksessa, jossa taimia on hehtaarilla 25000 kappaletta. Senga Senganan myyntikelpoinen sato oli samana vuonna noin 350 grammaa. Vuonna 2000 Kaunotar-lajikkeen sato oli noin 400 grammaa kasvia kohden, mikä vastaa yksirivi-istutuksessa noin kymmenen tonnin hehtaarisatoa. Senga Sengana- ja Bounty-lajikkeiden kasvikohtaiset myyntikelpoiset sadot olivat noin 600 ja 700 grammaa, mitkä vastaavat noin 15 ja 18 tonnin hehtaarisatoja. Koska varhaislajikkeen tärkeimmät ominaisuudet ovat aikaisuus ja kauniit, hyvänmakuiset marjat, on viiden tonnin sato ensimmäisenä ja kymmenen tonnin sato toisena satovuonna aikaiselle mansikkalajikkeelle hyvin riittävä. Tämä suuruiset sadot vastaavat Jonsok-lajikkeen satotasoa.

Kaunotar-lajikkeen marjat ovat kauniita, hyvänmakuisia ja usein makeita. Muodoltaan ne ovat pyöreän kiilamaisia. Niiden väri on tumman kirkkaanpunainen tai "sengana-lajikkeenpunainen" ja ne ovat myös sisältä hyvin värittyneitä. Marjan kiinteys on keskinkertainen; lähinnä Bounty-lajikkeen kiinteyttä vastaava. Kaunotar-kasvustoissa havaittiin selkeitä härmäoireita, mutta oleellista on, että härmää ei esiintynyt lainkaan marjoissa. Tyvimädän kestävyystestaus osoitti Kaunotar-lajikkeen olevan Polkalajikkeen tavoin melko altis tälle taudille (MTT, Päivi Parikka).

'Kaunotar' on talvehtinut Piikkiön kokeessa ja myös Laukaalla olleessa istutuksessa hyvin, lähes verrannelajikkeiden veroisesti. Lajike on kasvutavaltaan hillittykasvuinen ja keskinkertaisen tiheä. Rönsyjä 'Kaunotar' tuottaa normaalisti.

\section{'Cavendish'}

Kanadalainen Cavendish-lajike oli testattavana tilakokeissa vuosina 1999-2002. Lajike on peräisin Glooscap- ja Annapolis-lajikkeiden välisestä risteytyksestä. Se vastaa aikaisuudeltaan Polka-lajiketta. Kokeiden perusteella lajiketta voidaan suositella viljelyyn Suomen olosuhteissa erityisesti jäykähköillä savi- ja hiesupitoisilla maalajeilla. Kevyillä maalajeilla 'Polka' on yleensä ollut sekä sadon määrän että laadun suhteen parempi. Cavendish-lajikkeen marjan laatua on pidetty hyvänä; ja varsinkin maku on miellyttänyt monia maistelijoita. Marjojen väriä on tosin joskus moitittu hieman kirjavaksi, ja lajiketta 
pidetty epätasaisesti kypsyvänä.

Cavendish-lajikkeen kasvutapa on avoin, ja valo pääsee hyvin taimen keskiosiin. Tilakokeiden aikana ei sadossa juurikaan havaittu härmäisiä marjoja, vaikka härmätautia esiintyikin kasvustoissa. Härmäriskin vuoksi Cavendish-lajiketta ei kuitenkaan suositella istutettavaksi alueille, joilla on aikaisemmin esiintynyt runsaasti härmää muilla lajikkeilla. Lajikkeen harmaahomeen- ja sateenkestävyys vaikuttavat tilakoekokemusten perusteella hyvältä. Myös talvenkestävyys näyttäisi olevan hyvä.

\section{'Kent'}

Kanadassa jalostettu 'Kent' on peräisin risteytyksestä: ('Redgauntlet' x 'Tioga') x 'Raritan'. Tämä lajike oli myös testattavana tilakokeissa vuosina 1999-2002, ja sekin osoittautui mahdolliseksi vaihtoehdoksi viljelyyn. 'Kent' on Suomessa viljelykelpoinen: lajikkeen talvenkestävyys vaikuttaa hyvältä ja kasvustot ovat olleet hyvin terveitä. Voimakkaan kasvutavan vuoksi 'Kent' kannattaa istuttaa hieman muita lajikkeita harvempaan.

Keskimääräiseltä aikaisuudeltaan 'Kent' vastaa lähinnä Polka-lajiketta, mutta sen satokausi on usein poikkeuksellisen pitkä. Sadon määrässä ja laadussa 'Kent' ei kuitenkaan ole yleensä ollut Polka-lajikkeen veroinen. Lajikkeen marjat ovat kiinteäpintaisia, mutta käytännön kokemukset marjojen kuljetuskestävyydestä eivät aina ole olleet hyviä. Pähkylät erottuvat marjan pinnalta voimakkaasti, eikä marjojen maku ei ole saanut varauksetonta kiitosta.

\section{Lajikeseurantakokeiden kiinnostavia lajikkeita}

Seuraavassa esitellään joitakin lajikeseurantakokeissa kiinnostusta herättäneitä lajikkeita, jotka voisivat olla potentiaalisia viljelylajikkeita Suomessa. On kuitenkin muistettava, että lajikeseurantakokeet ovat luonteeltaan alustavia kokeita, eikä niiden pohjalta voida vielä tehdä viljelysuosituksia.

Kaikkien seuraavien uutuuksien kasvustoissa havaittiin ainakin jonkin verran talvivaurioita toisen istutusta seuranneen talven jälkeen. Mutta kokeissa lajikkeiden satopotentiaali ylsi vähintään Jonsoklajikkeen satotasoon.

\section{'Mira'}

Kanadalaisen 'Mira' on peräisin Scott- ja Honeoye-lajikkeiden välisestä risteytyksestä. 'Mira' oli testattavana lajikeseurantakokeissa sekä Piikkiössä että Mikkelissä. Lajike oli yhdestä kolmeen päivää Bounty-lajikketta aikaisempi ja sen marjakoko oli hyvä. Mira-kasvustot olivat melko voimakaskasvuisia, keskinkertaisen tiheitä ja härmäoireita niissä havaittiin vain vähän. Lajikkeen kartiomaiset marjat olivat kohtalaisen kiinteitä. Väriltään ne olivat tumman kirkkaanpunaisia tai senganan- punaisia. Marjojen maku oli satokautena 2001 hienoinen pettymys; aromi vaikutti melko heikolta ja happoisuus makeutta voimakkaammalta. Kiinnostava ominaisuus Mira-lajikkeessa, lupaavan satopotentiaalin lisäksi, on marjojen kiinteys.

\section{'Joliette'}

'Joliette' on myös jalostettu Kanadassa, ja se on peräisin risteytyksestä: ('Redchief' x 'Surecrop') x 'Jewel'. 'Joliette' oli mukana seurantakokeissa sekä Piikkiössä että Mikkelissä. Lajikkeen aikaisuus sijoittui Jonsok- ja Bounty-lajikkeiden aikaisuuksien keskivaiheelle. Kauppakelpoisen sadon määrän suhteen 'Joliette vastasi kokeessa Jonsok-lajiketta, mutta sen marjakoko oli suurempi. Piikkiön kokeesta poimitut ensimmäiset marjat painoivat jopa 33 grammaa, ja keskisadon marjapaino oli 16-19 grammaa. Vuoden 2001 satokauden alussa marjat olivat myös varsin kiiltäviä ja komeita, mutta ne kärsivät selvästi sateista. Marjojen väri vaihteli tiilenpunaisesta senganan-punaiseen, ja niiden kiinteys oli keskinkertainen. Makua pidettiin kohtalaisena. Muodoltaan marjat olivat leveän tai pyöreän kiilamaisia. Kasvustot olivat melko voimakaskasvuisia, mutta kasvutavaltaan avoimia. Niissä havaittiin keskinkertaisen voimakkaita härmäoireita.

Kiinnostava ominaisuus Joliette-lajikkeessa on hyvä marjakoko ja positiivista on myös kohtalaisen hyväksi arvioitu maku, vaikkei lajike varsinaiselta herkkumarjalta vaikuttanutkaan.

\section{'Kimberly'}

Hollantilainen Kimberly oli myös seurantakokeissa sekä Piikkiössä että Mikkelissä. Lajike kärsi kohtalaisia talvivaurioita. Sen aikaisuus sijoittui Jonsok- ja Bounty-lajikkeiden aikaisuuden keskivaiheelle. Lajikkeen marjat kypsyivät Piikkiössä noin kolme päivää myöhemmin kuin Jonsok-lajikkeen marjat. Seuraavana vuonna Mikkelissä lajikkeiden välinen kypsymisajankohdan ero oli viisi päivää. 
Kauppakelpoisen sadon määrät istutettua kasvia kohden vastasivat Jonsok -lajikkeen satotasoa; noin 200 grammaa Mikkelin ja 300 grammaa Piikkiön kokeessa. Marjakoko oli hyvä. Satokauden alussa Kimberlylajikkeen marjat olivat aika kauniita, mutta keskisadon paikkeilla niiden väri vaihteli paljon, tiilenpunaisesta senganan-punaiseen. Marjat olivat kiinteitä ja muodoltaan kartiomaisia tai leveän kartiomaisia, loppusadosta myös pyöreähköjä. Marjan mausta pidettiin, ja sitä kuvattiin hedelmäiseksi. Talvivaurioiden vuoksi Kimberly-kasvustot olivat epätasaisia, mutta lajike vaikuttaa kohtalaisen voimakaskasvuiselta ja keskinkertaisen tai kohtalaisen tiheältä. Kasvuston härmäoireet olivat melko vähäisiä eikä härmäisiä marjoja ollut sadossa lainkaan.

Kimberly-lajikkeessa eniten kiinnostusta herättävät hyvänmakuiset ja kiinteät marjat. Toisaalta ulkomaiset tiedot lajikkeen taudin alttiudesta saavat suhtautumaan siihen suurella varauksella. 'Kimberly on altis mustalaikkusienelle, ja esimerkiksi Tanskassa on tästä lajikkeesta löytynyt useita tautitapauksia.

\section{'Vima Zanta'}

Hollantilainen 'Vima Zanta' on Elsanta- ja Korona-lajikkeiden välinen risteytys. Lajike oli mukana lajikeseurantakokeessa Piikkiössä. Kahtena koevuotena sen aikaisuus vaihteli jonkin verran. Ensimmäisenä satokautena aikaisuus sijoittui Jonsok- ja Bounty-lajikkeiden keskivaiheelle. Toisena satovuonna aikaisuus läheni Jonsok-lajikkeen aikaisuutta, ollen vain pari päivää tätä myöhäisempi. Kauppakelpoinen sato kokeessa oli 294-514 grammaa istutettua kasvia kohden.

'Vima Zanta' oli kohtalaisen voimakaskasvuinen. Kasvustoissa oli voimakas härmäsaastunta, ja toisen satovuoden marjoista oli härmäisiä viitisen prosenttia. Marjat olivat kirkkaanpunaisia tai tummankirkkaanpunaisia, kiinteitä, ja niiden pinta oli kestävä. Maku arvosteltiin vuonna 2000 hyväksi, joskin hedelmäiseksi. Toisen vuoden makuarviot eivät olleet aivan yhtä positiivisia.

Vima Zanta-lajikkeen tekee kiinnostavaksi marjojen hyvä maku, kiinteys ja kohtalaisen aikainen sadon kypsyminen.

\section{'Florence'}

'Florence' on peräisin Englannista ja sen jalostuksessa on käytetty lajikkeita: 'Tioga', 'Redgauntlet' 'Wiltguard' 'Gorella' ja 'Providence'; risteytyskaava on monimutkainen. Lajike oli mukana lajikeseurantakokeessa Piikkiössä.

Florence-lajikkeen satokausi oli myöhäinen. Kokeessa marjat kypsyivät keskimäärin kahdesta viiteen päivää Bounty-lajikkeen satoa myöhemmin. Satotasoltaan 'Florence vastasi kokeessa Jonsoklajiketta. Lajikkeen sadosta oli toisena satovuonna kuutisen prosenttia härmän saastuttamaa. 'Marjat olivat hyvän kokoisia, kartiomaisia, kirkkaan tai tummankirkkaan punaisia, usein kiiltäviä ja niiden pinta oli aika kestävä. Kiinteys oli keskinkertainen tai kohtalaisen hyvä. Ensimmäisenä satovuonna marjojen pinnassa oli kirjavuutta, mutta toisena satovuonna marjat olivat parhaimmillaan komeita. Makua on koevuosien aikana kuvattu hyväksi tai kohtalaisen hyväksi. Kasvuvoimakkuudeltaan 'Florence' oli keskinkertainen ja härmäoireita esiintyi kasvustossa kohtalaisesti. 'Florence' kiinnostaa myöhäisenä lajikevaihtoehtona.

\section{Tulevaisuuden näkymä}

Kaikkien uusien lajikkeiden menestyminen ratkeaa lopulta vasta muutaman vuoden laajemman viljelyn jälkeen. Sitten kun lajike on kohdannut useat eri tavoin vaihtelevat vuosittaiset olosuhteet yhtä vaihtelevilla kasvupaikoilla, on lajikkeen viljelyarvo lopullisesti punnittu. Lajikeseurantakokeet ja niitä seuranneet tilakokeet ovat olleet hyvä järjestelmä uusien viljelykelpoisten lajikkeiden löytämiseksi ulkomaisesta lajiketarjonnasta. Jatkossa toiminta painottuu kuitenkin enemmän kotimaiseen mansikanjalostukseen, ja tulevina vuosina on odotettavissa uusia suomalasisia mansikkalajikkeita.

\section{Kirjallisuus}

Hietaranta, T. 2001. Uusia mansikkalajikkeita Euroopasta. Puutarha \& kauppa 47/2001 plus, p.16-17.

Hietaranta, T., Matala, V., Kinnanen, H. \& Tillanen, A. 2003. Uudet aikaiset mansikkalajikkeet kiven alla. Puutarha \& kauppa 25-26/2003, p.8-9.

Hietaranta, T. \& Tahvonen, R. 2003.Mansikkalajikkeiden jalostaminen. Loppuraportti. [verkkojulkaisu]. MTT:n selvityksiä 36. Viitattu 13.1.2004. Julkaistu 20.05.2003. Saatavilla Internetissä: http://www.mtt.fi/mtts/. ISBN 951-729-766-1

Hietaranta, T., Tahvonen, R. \& Parikka, P. 2003.Uusi aikainen Kaunotar-lajike Puutarha \& kauppa 13/2003, p.16. 
SUOMEN MAATALOUSTIETEELLISEN SEURAN TIEDOTE NRO 19

Matala, V.\& Tuovinen, T. 2003. Mansikan lajikekokeet käytännön viljelmillä. MTT.n selvityksiä 26. 33 s. 